\title{
MODAL SOSIAL DALAM PENGELOLAAN HUTAN RAKYAT: STUDI KASUS DI DESA BERJO NGARGOYOSO KARANGANYAR JAWA TENGAH
}

\author{
Social Capital in Community Forest Management: Case Study in Berjo Village \\ Ngargoyoso, Karanganyar, Central Java \\ Khabib Bima Setiyawan* \\ Program Studi Magister Sosiologi \\ Fakultas Ilmu Sosial dan Politik, Universitas Sebelas Maret, Surakarta \\ *Kontak penulis: setiyawankhabibbima@gmail.com
}

\begin{abstract}
Forest is the source of livelihood of the community. Forest sustainbility management become important thing to do to ensure the sustainbility of the forest. This research discuss about forest management strategies in the Berjo village, which consist of three different institutions, they are : Taman Hutan Raya (Tahura), Perusahaan Hutan Negara Indonesia (Perhutani), and Lembaga Masyarakat Desa Hutan (LMDH). This research was conducted in the village of Berjo, Karangayar city. The aim of this research is to find out the forest management strategies. Methodes that applied in this research is qualitaive by using case studies approach. Purposive sampling were used to select the respondents. The results showed that forest management were achieved by collaboration among Government and non government institutions. Sosial Bonding Capital from both,allows interaction in sharing knowledge and so as become bonding among groups. Social Bonding which owned by LMDH and Tahura were on the intermediate level which means they obey formal but also approached the level of values, culture, and perception. Meanwhile, the relationship between LMDH and Tahura was on the level of social capital that embraced a formal values in corresponding their jobs desk which are conservation and production of the forest. LMDH cooperated with Perhutani in forest management through partnership. They cooperated in the safeguarding of the forests and open tourist attraction. Whereas in the greening of the forest, the Perhutani, the LMDH Tahura and do reforestation.
\end{abstract}

\begin{abstract}
Abstrak
Hutan adalah sumber mata pencaharian masyarakat. Pengelolaan kelestarian hutan menjadi hal penting yang harus dilakukan untuk memastikan kelestarian hutan. Penelitian ini membahas tentang strategi pengelolaan hutan di desa Berjo, yang terdiri dari tiga lembaga berbeda, yaitu: Taman Hutan Raya (Tahura), Perusahaan Hutan Negara Indonesia (Perhutani), dan Lembaga Masyarakat Desa Hutan (LMDH). Penelitian ini dilakukan di desa Berjo, kota Karangayar. Tujuan dari penelitian ini adalah untuk mengetahui strategi pengelolaan hutan. Metode yang diterapkan dalam penelitian ini adalah kualitatif dengan menggunakan pendekatan studi kasus. Purposive sampling digunakan untuk memilih responden. Hasil penelitian menunjukkan bahwa pengelolaan hutan dicapai dengan kolaborasi antara pemerintah dan lembaga non pemerintah. Modal Ikatan Sosial dari keduanya, memungkinkan interaksi dalam berbagi pengetahuan dan sehingga menjadi ikatan antar kelompok. Ikatan sosial yang dimiliki oleh $\mathrm{LMDH}$ dan Tahura berada pada tingkat menengah yang berarti
\end{abstract}


mereka mematuhi formal tetapi juga mendekati tingkat nilai, budaya, dan persepsi. Sementara itu, hubungan antara $\mathrm{LMDH}$ dan Tahura berada pada tingkat modal sosial yang menganut nilai-nilai formal dalam menyesuaikan meja kerja mereka yang merupakan konservasi dan produksi hutan. LMDH bekerja sama dengan Perhutani dalam pengelolaan hutan melalui kemitraan. Mereka bekerja sama dalam melindungi hutan dan membuka objek wisata. Sedangkan di penghijauan hutan, Perhutani, LMDH Tahura dan melakukan reboisasi.

Keywords: forest, management, social capital, bonding social capital.

Sitasi: Setiyawan, Bima K., 2019. Modal Sosial Pengelolaan Hutan Rakyat : Studi Kasus Di Desa Berjo Ngargoyoso Karanganyar Jawa Tengah, JSEP 15(2): 156 - 163.

\section{Pendahuluan}

Sebagai salah satu negara di Asia Tenggara Indonesia dijuluki sebagai negara maritim dan negara hutan tropis (Nugroho, 2010). Hutan memiliki arti penting terutama bagi masyarakat di sekitarnya yang memanfaatkan hasil hutan untuk dijadikan pemenuh kebutuhan sehari-hari Hutan rakyat sebagai salah satu sumber pendapatan negara belum dikelola dengan optimal. Statistik kehutanan mencatat bahwa lahan kritis di Provinsi Jawa Tengah telah mencapai 18.238,90 juta ha (BPS, 2016). Pembangunan hutan rakyat di sekitar kawasan hutan lindung mempunyai fungsi strategis untuk meningkatkan pendapatan masyarakat sekitar hutan dan mengurangi ketergantungan masyarakat terhadap sumberdaya hutan yang potensinya terus menurun, terutama dengan munculnya hutan-hutan kritis (Handoko, et.al, 2012).

Pengelolaan yang mengedepankan tujuan kolektif antara pemerintah dan masyarakat menjadi penting demi menjaga kelestarian hutan masa kini dan masa datang. Hutan rakyat perlu dikembangkan melalui penyediaan bibit bagi hutan yang baru dipanen. Disamping itu, bagi perusahaan dan rakyat yang memanfaatkan hasil hutan perlu melakukan pengamanan kayu dan keharusan untuk melakukan reboisasi. Seluruh pengelolaan hutan tersebut harus diarahkan untuk mencegah kerusakan dan menjaga kelestarian hutan (Hanani et.al, 2003).

Desa Berjo di Kecamatan Ngargoyoso Kabupaten Karanganyar Provinsi Jawa Tengah merupakan desa yang sebagian besar wilayahnya adalah hutan yang berada di bawah Gunung Lawu. Dengan adanya sumberdaya alam (SDA) tersebut, Desa Berjo berupaya untuk mengelola hutan agar dapat dimanfaatkan secara efektif dan efisien demi kesejahteraan masyarakat sekitar. Dalam Pengelolaannya, terdapat tiga pihak yaitu Taman Hutan Raya (Tahura), Perusahaan Hutan Negara Indonesia (Perhutani), dan Lembaga Masyarakat Desa Hutan (LMDH). Ketiganya memiliki tugas dan fungsi masing-masing yang terintegrasi berdasarkan tujuan untuk mengoptimalkan pengelolaan hutan agar tetap lestari. Tidak dapat dipungkiri juga bahwa kegitanya melakukan kolaborasi dalam mengelola hutan sehingga memungkinkan adanya interaksi yang terbentuk akibat adanya modal sosial.

Modal sosial sebagai segala sesuatu yang berkaitan dengan kerja sama dalam masyarakat atau bangsa untuk mencapai kapasitas hidup yang lebih baik, ditopang oleh nilai dan norma yang menjadi unsur utamanya seperti rasa saling mempercayai 
(mutual trust), ketimbal-balikan (reciprocity), aturan-aturan kolektif (social norms) dalam suatu masyarakat atau bangsa (Hasbullah, 2006; Nizar et.al, 2016). Menurut Putnam tiga dimensi sosial yang harus ada yaitu jaringan atau hubungan sosial, norma, dan kepercayaan (Slamet, 2012; Heliaway et.al, 2015).

Dalam modal sosial terdapat norma informal dan bukan aturan konstitusi formal, ada aktivitas relasi antar dua orang atau lebih, ada resiprositas (hubungan timbal-balik), diwujudkan hanya dalam hubungan yang sangat erat (pertemanan) bukan hubungan formal, dan untuk pencapaian tujuan (Nizar et.al, 2016). Fukuyama (1995) membandingkan karakteristik masyarakat Asia Tenggara yang tingkat hubungan sosialnya tinggi dengan masyarakat Eropa dan Amerika yang cenderung individualistik.

Modal sosial juga inheren dalam struktur relasi antar individu. Struktur relasi dan jaringan inilah yang menciptakan berbagai ragam kewajiban sosial, menciptakan saling percaya, membawa saluran informasi dan menetapkan norma-norma dan sanksi sosial bagi para anggotanya (Nizar et.al, 2016). Dalam hal ini modal sosial berperspektif hubungan dengan sesama (individu) sebagai unit analisisnya. Sementara itu, modal sosial juga mencakup perspektif yang lebih luas yakni segala sesuatu yang membuat masyarakat bersekutu untuk mencapai tujuan bersama atas dasar kebersamaan, dan di dalamnya diikat oleh nilai-nilai dan norma-norma yang tumbuh dan dipatuhi.

Dalam konteks keeratan dan keberagaman pihak-pihak yang berinteraksi, modal sosial terklasifikasi menjadi tiga jenis modal sosial, yaitu: modal sosial yang mengikat (bonding social capital), modal sosial yang menjembatani (bridging social capital) dan modal sosial yang menghubungkan (linking social capital) (Wooolcock, 2001). Bonding social capital adalah ikatan perasaan diantara orang-orang yang ada dalam situasi yang sama, semisal ikatan keluarga, kawan karib, dan ketetanggaan. Bridging social capital adalah modal sosial yang menjembatani antar unit sosial secara horizontal seperti antar kelompok, antar etnis, antar suku dan sebagainya. Linking social capital adalah modal sosial yang menghubungkan antar unit secara vertikal dari beragam latar belakang, semisal satu komunitas dengan pihak luar, dan ikatan yang demikian akan memungkinkan kita bisa mengakses beragam sumber untuk kepentingan komunitas (Field, 2008)

Tulisan ini mengkaji mengenai pengelolaan hutan yang melibatkan LMDH, Perhutani dan Tahura. Pertanyaan yang hendak dijawab adalah bagaiamana peran modal sosial dalam pengelolaan hutan sehingga mampu menjadikan masyarakat di sekitar hutan lebih sejahtera.

\section{Metode Penelitian}

Penelitian ini merupakan penelitian kualitatif yang berlokasi di Desa Berjo, Kecamatan Ngargoyoso, Karanganyar, Jawa Tengah. Penelitian dilaksanakan pada bulan April-Mei 2017. Desa ini mempunyai luas wilayah 1.623,865 Ha, terletak di lereng Gunung Lawu. Desa Berjo memiliki topografi berupa daerah ketinggian, berada di ketinggian $\pm 1.500 \mathrm{mdpl}$, dengan suhu udara rata - rata $\pm 22{ }^{\circ} \mathrm{C}$ sampai dengan $32{ }^{\circ} \mathrm{C}$ dan beriklim tropis. Sebelah utara Desa Berjo dibatasi oleh desa Girimulyo, sebelah timur dibatasi oleh hutan Lawu, sebelah selatan dibatasi oleh Kecamatan Tawangmangu, dan sebelah barat dibatasi oleh Desa Puntukrejo. 
Penelitian ini dimulai dari persiapan dalam melakukan perizinan kepada pihak terkait dalam hal ini LMDH, Perhutani, dan TAHURA kemudian dilanjutkan dengan proses pengambilan data melalui observasi, wawancara dan studi dokumentasi. Dalam memilih informan, peneliti menggunakan teknik purposive yaitu dengan melakukan indepth interview untuk mendapatkan data yang mendalam. Peneliti menggunakan studi dokumentasi berupa catatan selama proses penelitian, dan rekaman suara. Setelah data terpenuhi, peneliti melakukan analisis interaktif fungsional yang berpangkal dari empat kegiatan yaitu pengumpulan data, reduksi data, penyajian data dan uji validitas data menggunakan triangulasi sumber (Miles et al, 2014).

\section{Hasil dan Pembahasan}

\subsection{Lembaga Utama dalam Pengelolaan Hutan Rakyat}

Dalam pengelolaan hutan rakyat di Desa Berjo terdapat tiga pihak utama yang berperan dan berinteraksi satu sama lain. Ketiga pihak tersebut adalah Lembaga Masyarakat Desa Hutan (LMDH), Perusahaan Hutan Negara Indonesia (Perhutani), dan Taman Hutan Raya (Tahura). Interaksi antara ketiganya menciptakan sebuah ikatan kebersamaan dalam mendorong berkembangnya hutan rakyat.

LMDH merupakan sebuah organisasi yang bertujuan dalam peningkatan kesejahteraan masyarakat sekitar kawasan hutan dan pelestarian hutan. Di Desa Berjo berkembang LMDH bernama Wana Hijau Lestari. LMDH Wana Hijau Lestari lahir pada tahun 2001 dan beranggotakan masyarakat Desa Berjo, Kecamatan Ngargoyoso, Kabupaten Karanganyar. LMDH merupakan wadah pengorganisasian diri masyarakat dalam mengelola sumberdaya hutan baik untuk fungsi ekonomi dalam pemanfaatan hasil hutan maupun untuk fungsi ekologis dalam pemeliharaan keanekaragaman hayati dalam hutan.

Perhutani adalah Badan Usaha Milik Negara di Indonesia yang bertugas untuk perencanaan, pengurusan, pengusahaan dan perlindungan di wilayah kerja. Perhutani dibagi menjadi beberapa organisasi pengelola berupa Kepala Resort Pangkuan Hutan. Dalam Pengelolaan Hutan Lawu terdapat enam Kepala Resort Pangkuan Hutan (KRPH) yakni KRPH Gunung Bromo, KRPH Nglerak, KRPH Blumbang, KRPH Banjarsari, KRPH Telaga Dringo, dan KRPH Tambak. KRPH yang berada di Desa Berjo yaitu KRPH Tambak dengan luas wilayah sekitar 1.200 Ha.

Tahura merupakan institusi di bawah Pemerintah Provinsi Jawa Tengah. Tahura Mangkunagoro I yang terletak di lereng Gunung Lawu sisi Barat saat ini merupakan satu-satunya Tahura yang ada di Jawa Tengah dan satu-satunya kawasan hutan konservasi yang dikelola oleh Pemerintah Daerah yang juga menjadi kebanggaan daerah. Tahura Mangkunagoro I merupakan kawasan pelestarian alam dengan luas $\pm 231,3$ ha terletak di lereng Gunung Lawu yang secara administratif berada di Desa Berjo, Ngargoyoso, Karanganyar, Jawa Tengah. Secara geografis terletak $111^{\circ} 8^{\prime} 13^{\prime \prime}-111^{\circ} 8^{\prime} 58^{\prime \prime}$ BT dan $7^{\circ} 37^{\prime} 20^{\prime \prime}-7^{\circ} 38^{\prime} 33^{\prime \prime} \mathrm{LS}$. 


\subsection{Modal Sosial dalam Pengelolaan Hutan Rakyat}

Modal sosial yang lebih kuat dalam pengelolaan hutan rakyat di Desa Berjo adalah modal sosial mengikat (bonding social capital) karena menurut penuturan ketiga pihak yang terlibat dalam pengelolaan hutan di Desa Berjo kedekatan antara ketiganya dalam hal jarak tempat dan hubungan sosial merupakan faktor yang sangat mendukung dalam koordinasi. Modal sosial menghubungkan (linking social capital) hubungannya lebih pada tanggungjawab antar unsur pengelola kepada lembaga secara hirarki. Modal sosial menjembatani (bridging social capital) dalam pengelolaan hutan rakyat belum signifikan karena pihak luar belum ada yang bergabung dalam pengelolaan hutan karena selama ini hutan masih dikelola secara mandiri.

Tabel 1

Identifikasi Bonding Social Capital pada Hutan Rakyat di Desa Berjo

\begin{tabular}{cll}
\hline No & $\begin{array}{l}\text { Unsur Modal } \\
\text { Sosial }\end{array}$ & \multicolumn{1}{c}{ Ciri Bonding Social Capital } \\
\hline 1 & Jaringan sosial & $\begin{array}{l}\text { Hubungan pertetanggaan yang berdekatan antara } \\
\text { Perhutani, Tahura, dan LMDH yang terletak di Dusun } \\
\end{array}$ \\
& & $\begin{array}{l}\text { Tambak Desa Berjo dalam satu Resort Pangkuan Hutan } \\
\text { (RPH) Tambak. Jejaring antara ketiganya menciptakan }\end{array}$ \\
& & ikatan yang melahirkan kapasitas untuk mewujudkan \\
& & tujuan bersama terkait kesejahteraan masyarakat sekitar \\
& hutan dan kelestarian ekosistem hutan.
\end{tabular}

2 Kesalingpercay 1. Kesalingpercayaan antara Perhutani dan Tahura aan dalam saling bantu sumberdaya untuk beraktivitas sesuai tugas dan fungsi masing-masing.

2. Kesalingpercayaan antara Tahura dengan LMDH dalam saling dukung melalui kerja bakti dan aktivitas bersama dalam reboisasi hutan.

3. Perhutani dengan LMDH membangunan mitra pertemanan yang menganut nilai-nilai simpati, saling percaya dan bertukar kebajikan pada level kultural.

3 Norma sosial Berlaku norma sosial yang dipatuhi oleh Perhutani dan LMDH mencakup pengaturan hubungan kemitraan dalam melestarikan hutan, pengaturan tentang kepemilikan kolektif atas berbagai unsur yang dikelola oleh kelompok kerja (pokja), dan pengaturan tentang diperbolehkannya masyarakat mengambil hasil rumput untuk pakan hewan ternak dan ranting kayu untuk bahan bakar.

4 Hubungan 1. Hubungan resiprositas dalam membagi pengetahuan timbal balik melalui focus group discussion (FGD) yang rutin dilaksanakan tiap bulan antara Perhutani, Tahura, dan LMDH di lingkungan warga Dusun Tambak Desa Berjo.

2. Masyarakat mengambil rumput dan ranting kayu sekaligus membantu Perhutani mengamankan hutan 
Dalam pengelolaan hutan, mekanisme bonding social capital pada level kultural berlansung antara LMDH dan Perhutani yang bermitra dalam pengelolaan hutan rakyat. Hubungan kemitraan antara kedua belah pihak bersifat kekeluargaan dan lebih memegang norma informal sesuai kultur. Kerjasama dilakukan dalam hal pengamanan hutan, penghijauan, dan pembukaan objek wisata. Kedua belah pihak merasa sudah saling mempercayai dalam menjaga keamanan hutan, walaupun secara aturan formal menurut Peraturan Pemerintah Republik Indonesia Nomor 24 Tahun 2010 Tentang Penggunaan Kawasan Hutan Pasal 1 (4) diatur bahwa "hutan lindung adalah kawasan hutan yang mempunyai fungsi pokok sebagai perlindungan sistem penyangga kehidupan untuk mengatur tata air, mencegah banjir, mengendalikan erosi, mencegah intrusi air laut, dan memelihara kesuburan tanah."

Namun demikian, secara norma informal terdapat kesepakatan dari nenek moyang yang sampai sekarang masih diberlakukan antara Perhutani dan masyarakat (LMDH) yaitu setiap warga diberikan hak seluas 0,25 ha hanya untuk mengambil rumput tanpa mengubah struktur tanah. Kesapakatan tersebut menyebabkan terjadinya hubungan resiprositas antara Perutani dan LMDH. Perhutani merasa diuntungkan dengan aktivitas rutin setiap hari oleh pengaram (sebutan bagi pengambil rumput) yang setiap hari masuk hutan mengambil rumput sekaligus sebagai upaya pengamanan hutan oleh masyarakat mengingat hanya terdapat empat petugas Perhutani di Resort Pangkuan Hutan Tambak. LMDH juga diuntungkan dengan pengaram yang mengambil hasil rumput untuk memberi makan hewan ternak. Keuntungan lain yaitu menjaga pohon agar dapat menyerap air secara maksimal.

Program penghijauan dilakukan juga oleh LMDH dan Perhutani sebagai upaya menjaga kelestarian ekosistem hutan rayat di Desa Berjo secara gotong royong bekerja tanpa imbalan. Pembukaan objek wisata juga menjadi progam kerja yang dilaksanakan oleh LMDH dan Perhutani, biaya operasional ditanggung bersama dan pengerjaan juga dilakukan dengan sistem kerja bakti. Penyelenggaraan program kerja tersebut sekaligus berfungsi sebagai unit pemantauan oleh LMDH dan Perhutani dalam pengamanan hutan karena jalur wisata berdekatan dengan area hutan. Rasa simpati juga ditunjukkan oleh kedua belah pihak salah satunya dengan menjenguk apabila ada salah satu anggota yang sakit.

Modal sosial antara LMDH dan Perhutani yang berkembang selama ini mengarah pada terbentuknya tiga level modal sosial, yakni pada level nilai, intitusi, dan mekanisme, sebagaimana tergambar berikut.

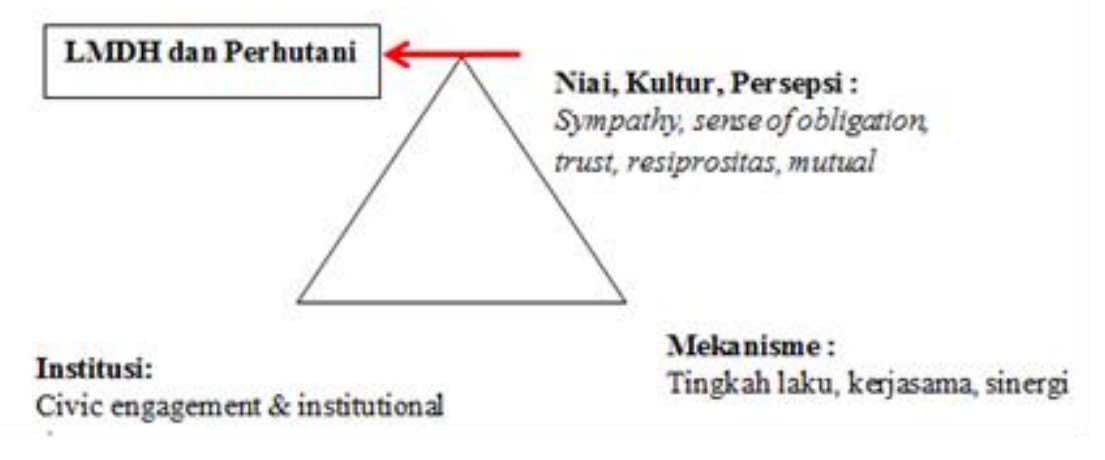

Gambar 1. Level modal sosial LMDH dan Perhutani 
Diantara ketiga pihak yang mengelola hutan, level modal sosial tertinggi dimiliki oleh LMDH dan Perhutani yang memang merupakan mitra dalam menjalankan tugas dan fungsi. Sedangkan Tahura sebagai institusi Provinsi menjadi pihak yang memastikan ekosistem hutan tetap terjaga melalui upaya konservasi yang dilakukan bersama LMDH.

Tata kelola kolaboratif berfokus pada kebijakan dan isu publik. Fokus pada isu publik membedakan tata kelola kolaboratif dari bentuk consensus dalam pengambilan keputusan, seperti penyelesaian perselisihan alternatif atau mediasi transformatif. Meskipun agensi dapat melakukan penyelesaian sengketa atau mediasi untuk mengurangi konflik sosial atau konflik politik, teknik ini sering digunakan untuk menangani konflik pribadi. Bahkan, resolusi perselisihan atau mediasi publik dapat dirancang hanya untuk menyelesaikan sengketa pribadi (Ansell and Gash, 2007: 547) Dalam hubungan tata kelola kolaboratif (collaborative governance) antar pengelola hutan rakyat berlaku norma formal secara intitusional. Kondisi seperti ini juga ditemukan oleh Ali et.al (2016) pada kasus perkembangan hutan rakyat di Kabupaten Konawe Selatan (Sulawesi Tenggara) yang di dalamnya berbagai pihak berkontribusi.

Dalam perjalanannya, bonding social capital yang berfungsi dalam perkembangan hutan rakyat di Desa Berjo, kondisi yang muncul memungkinkan adanya hubungan berdasarkan norma informal secara kultural. Dalam konteks ini, perencanaan strategis hampir selalu dinilai dari "apa yang terjadi". Istilah tata kelola yang merupakan terjemahan dari "corporate governance" dimana sering kali metafora yang digunakan untuk menggambarkan esensi dari pengertian ini adalah mengendalikan dan menahkodai sebuah kapal (the idea of steering or captaining a ship) (Farrar dan White, 2001). Bila modal sosial yang mengikat antar pihak bekerja dengan efektif maka kehadiran nakhoda sebenarnya tidak signifikan, karena antar pihak diikat untuk mencapai tujuan bersama melalui bekerjanya bonding social capital.

\section{Kesimpulan}

Dalam pengelolaan hutan di Desa Berjo, terdapat tiga pihak yang berkolaborasi yaitu LMDH, Perhutani, dan Tahura. LMDH sebagai mitra Perhutani melakukan kegiatan dalam pengelolaan hutan yang bersifat resiprositas dalam bentuk reboisasi hutan secara gotong royong, pelaksanaan program kerja pembukaan objek wisata, dan pengamanan hutan setiap masyarakat untuk mengambil rumput.

Kesejahteraan masyarakat hutan dicapai melalui mitra dengan Perhutani dalam mengambil rumput untuk pakan hewan ternak dan ranting untuk bahan bakar, kegiatan ke hutan dilaksanakan hampir oleh semua masyarakat di Desa Berjo terutama di kawasan sekitar hutan. Sedangkan Tahura juga melaksanakan tupoksi dalam upaya pelestarian hutan secara konservatif dan melalui cara reboisasi. Ketiga pihak pengelola hutan juga melakukan pertemuan rutin sebagai upaya koordinasi dalam pelestarian hutan secara kolektif.

Fungsi-fungsi yang dimainkan masing-masing pihak berjalan efektif karena adanya modal sosial di antara mereka. Modal sosial tersebut mengikat mereka untuk mencapai tujuan bersama melalui bekerjanya unsur kesalingpercayaan (mutual trust), jaringan sosial (social networking), kepatuhan kepada norma sosial (compliance to social norms) dan hubungan resiprositas (reciprocity relationship). Unsur-unsur ini telah bekerja sebagai perekat sosial (social glue) antara LMDH, Perhutani dan Tahura dalam berkolaborasi untuk perwujudan tujuan hutan rakyat yakni kesejahteraan dan kelestarian.

\section{Daftar Pustaka}

Ali, M.S.S, A. Nikoyan, D. Salman, E.B. Demmalino, I. Summase, 2016. Multi-Actors Collaboration in Ecolabelling Community Teak Forest Management in Southeast Sulawesi Province, Indonesia. IJAS, Vol.3, Issu 1. 
Ansell dan Gash, 2007. Collaborative Governance in Theory and Practice. Journal of Public Administration Research and Theory. Oxford : Oxford University Press, 547.

Farrar, J dan D.G. White, 2012. Guide lines for the Validation of Chemical Methods for the FDA Program.

Badan Pusat Statisik Provinsi Jawa Tengah. 2016. Luas Lahan Kritis di Luar Kawasan Hutan Menurut Kabupaten/Kota di Provinsi Jawa Tengah.

Field, John. 2008. Social Capital, 2nd Ed. Roudledge, Canada : USA.

Fukuyama, F.,1995. Trust: The Social Virtues and the Creation of Prosperity. New York: Free Press.

Handoko C, C. Yudilastiantoro, dan Agus Sukito. 2012. Identifikasi Tahapan Faktor-Faktor Sosial Pembangunan Hutan Rakyat di Sekitar Kawasan Hutan Lindung. Jurnal Penelitian Kehutanan Wallacea, Vol.1, No.2

Hanani, N., Jabal, T.I., Mangku, P. 2003. Strategi Pembangunan Pertanian, Sebuah Pemikiran Baru. Yogya: Pustaka Jogja Mandiri.

Heliawaty, M. S.S. Ali, D. Salman, R. Mappangaja, 2015. Social Capital And Economic Behavior of Farmers. International Journal of Scientific and Technology Research. Volume 4, Issue 0.1

Miles, M.B, Hubermas, A.M, dan Saldana, J., 2014. Qualitative Data Analysis, A Methods Sourcebook Edition 3. USA : Sage Publications

Nizar, A., M.S.S. Ali, D. Salman, E. Demmalino, 2016. Social Capital: The Historical Emergence And Its Implications To Agricultural Development Program. International Journal of Scientific and Technology Research. Volume 5, Issue 07.

Nugroho, B. 2010. Pembangunan Kelembagaan Pinjaman Dana Bergulir Hutan Rakyat. Jurnal of Tropical Forest Management, Vol.XVI, No.3.

Slamet, Y. 2012. Modal Sosial dan Kemiskinan. Surakarta: UNS Press. 